\title{
Experiências educativo-musicais na formação de um habitus musical
}

\author{
Educational-musical experiences in the formation of a musical habitus
}

Experiencias educativo-musicales en la formación de un habitus musical

\author{
Marcelo Kaczan \\ Secretaria da Educação Básica do Ceará, Professor. \\ https://orcid.org/0000-0001-5045-8034 \\ Pedro Rogério² \\ Universidade Federal do Ceará, Professor. \\ https://orcid.org/0000-0002-5306-3641 \\ Maria Anita Vieira Lustosa Kaczan ${ }^{3}$ \\ Universidade Estadual do Ceará, Professora. \\ https://orcid.org/0000-0001-7945-1119
}

Resumo: Debate-se, neste escrito, a importância de se reafirmar o ensino de música nos espaços educativos, garantindo sua permanência no âmbito da escola regular. Assim, tem-se aqui como objetivo primordial apresentar a relevância da utilização de práticas educativo-musicais criativas para o ensino de música (FONTERRADA, 2015) como elemento potencializador do desenvolvimento humano, cognitivo, crítico, emocional, político e social. Essa maneira de ensinar música, com esteio em práticas criativas nas salas de aulas, traz múltiplas possibilidades de renovar o ensino de música e de se instaurar um habitus musical - uma cultura musical - ampliando o seu alcance ao maior número possível de estudantes. 0 motor central das discussões é a necessidade de se reinventar o ensino de música ante a hegemonia da Indústria Cultural, propondo práticas diversificadas que incentivem a criação e a fruição, que possam romper com o ensino tradicional de música padronizado e com a lógica do consumo mercadológico que o repertório comercial forma nos ouvintes. É necessário incentivar a criação de experiências diversas consideradas singulares em razão do processo massivo que apenas reproduz modelos prontos e legitimados socialmente. Assim, é urgente investir em práticas criativas diferentes das atuais formas de ensinar música na escola.

Palavras-chave: Ensino de Música. Práticas Criativas. Habitus Musical.

\footnotetext{
Mestre e doutorando em educação pela Universidade Federal do Ceará.

Doutor em Educação pela Universidade Federal do Ceará; pós-doutorando em Psicologia Social pela Universidad de Valladolid.

3 Doutora em Educação Brasileira pela Universidade Federal do Ceará; Mestre em Educação pela Universidade Federal do Ceará.
} 
Abstract: This paper discusses the importance of teaching music in educational spaces, ensuring its permanence within the scope of regular schools. Its primary objective is to show the relevance of using creative educational-musical practices for the teaching of music (FONTERRADA, 2015) as an element that enhances human, cognitive, critical, emotional, political and social development. This way of teaching music, based on creative practices, brings multiple possibilities to renew the teaching of music, and to establish a musical habitus - a musical culture - expanding its reach to the largest possible number of students. The central engine of the discussions is the need to reinvent music teaching in the face of the hegemony of the Cultural Industry. The text proposes diversified practices that encourage creation and enjoyment, which can break with the traditional teaching of standardized music and with the logic of market consumption that the commercial repertoire forms in listeners. It is necessary to encourage the creation of diverse experiences considered singular due to the massive process that only reproduces ready and socially legitimized models. Thus, it is urgent to invest in creative practices different from the current ways of teaching music at school.

Keywords: Music teaching. Creative Practices. Musical Habitus.

Resumen: Se debate, en este escrito, la importancia de reafirmar la enseñanza de la música en espacios educativos, garantizando su permanencia en el ámbito escolar. Por lo tanto, el objetivo principal aquí es presentar la relevancia del uso de prácticas creativas educativo-musicales para la enseñanza de la música (FONTERRADA, 2015) como un elemento que mejora el desarrollo humano, cognitivo, crítico, emocional, político y social. Esta forma de enseñar música, basada en prácticas creativas en el aula, ofrece múltiples posibilidades para renovar la enseñanza de la música y establecer un habitus musical, una cultura musical, ampliando su alcance al mayor número posible de estudiantes. Lo más importante de las discusiones es la necesidad de reinventar la enseñanza de la música frente a la hegemonía de la Industria Cultural, proponiendo prácticas diversificadas que fomenten la creación y el desarrollo, que puedan romper con la enseñanza tradicional de la música estandarizada y con la lógica del consumo del mercado que el repertorio comercial se forma en los oyentes. Es necesario alentar la creación de diversas experiencias consideradas singulares a causa del proceso masivo que solo reproduce modelos listos y socialmente legitimados. Por lo tanto, se hace urgente invertir en prácticas creativas diferentes de las formas actuales de enseñar música en la escuela.

Palabras clave: Enseñanza de la Música. Prácticas Creativas. Habitus Musical.

Recebido em 7 de fevereiro de 2020

Aceito em 25 de junho de 2020

Publicado em 28 de agosto de 2020 


\title{
1 INTRODUÇÃO
}

\author{
"Eis a nova orquestra: o universo sonoro! \\ E os músicos: qualquer um e qualquer coisa que soe!' \\ Murray Schafer
}

Neste artigo, debatemos a importância de se reafirmar o ensino de música nos espaços educativos, garantindo sua permanência no âmbito da escola regular. Assim, temos aqui como objetivo primordial apresentar a relevância da utilização de práticas educativomusicais criativas para o ensino de música (FONTERRADA, 2015) como elemento potencializador do desenvolvimento humano, cognitivo, crítico, emocional, político e social. Essa forma de ensinar música, com esteio em práticas criativas nas salas de aulas, traz múltiplas possibilidades de renovar o ensino de música e de se instaurar um habitus musical - uma cultura musical ampliando o seu alcance ao maior número possível de estudantes.

0 habitus, conceito que se pede por empréstimo a Bourdieu (1998), para referendar a instauração de uma cultura musical, por meio do ensino de música nas escolas, deve ser praticado em experimentações educativo-musicais, porquanto, ao ser incorporado, promove subjetivações com arrimo nas ditas práticas pedagógicas. Essas vivências são transubstanciadas como resiliência e por ele ressignificadas, como implicações dessas experiências curriculares.

Essa proposta metodológica para o ensino de música se coaduna com o pensamento de Peñalba (2017), Fonterrada (2015), Penna (2014), Schafer (2011, 2009), Bastian (2009) e demais pesquisadores e pedagogos musicais que se posicionam no mesmo direcionamento: o de introduzir vivências musicais ativas nas quais os educandos possam experimentar e participar ativamente no processo de elaboração do conhecimento.

Ao fazermos um estudo sobre o percurso da música no cenário educacional, é possível destacar que ela sempre figurou com relativa importância, sem, no entanto, afirmarse como disciplina obrigatória. ${ }^{4} 0$ uso de músicas diversas nas salas de aula funciona, em grande parte, como metodologia auxiliar que permite ao professor suavizar a rotina das atividades escolares. Em geral, entretanto, os professores ainda não perceberam o poderoso impacto social e político dessa atividade na formação dos estudantes.

Desse modo, é possível identificar o fato de que parte dos docentes, porque recebem influências das políticas curriculares vigentes, que absorvem em grande medida a cultura de massa e políticas educacionais de governo que não valorizam o ensino de música,

\footnotetext{
4 No Brasil, com a promulgação da Lei n. 11.769/2008, firmou-se a obrigatoriedade da música na escola, após mais de 40 anos de ausência e irregularidade no currículo escolar, sendo esta apenas um componente curricular obrigatório e não exclusivo. Assim como a referida lei, as Leis n. 13.278/2016 e n. 13.415/2017 também não conferiram ainda à música o status de disciplina.
} 
ainda aplicam essas experiências musicais como uma espécie de adorno ou apenas para o entretenimento dos estudantes, relegando a música a um papel secundário, sem valorizar o potencial transformador que ela exerce no processo de ensino e aprendizagem e nas relações socioafetivas.

No Brasil, nas primeiras décadas do século XXl, ainda é possível identificar a "ausência" ou uma permanência irregular do ensino de música e de todas as artes no universo escolar, fato este que consideramos prejuízo irreparável para a formação humana dos jovens estudantes. Peñalba (2017, p. 116) adverte sobre uma "crise de nível global" que o ensino de música enfrenta na atualidade. Esse quadro se acirra no contexto da sociedade neoliberal, em que se percebem o desprestígio e a secundarização do ensino de música, e se reflete no campo das políticas públicas de educação.

No Brasil, a proposta da Base Nacional Comum Curricular (BNCC) prevê a preponderância de disciplinas como português, matemática e língua estrangeira de forma obrigatória, deslocando outras disciplinas - artes, filosofia, sociologia - para a parte flexível do currículo. Destarte, a BNCC constrói uma retórica conceitual que considera a importância da arte para os sujeitos, todavia não a operacionaliza diante do currículo. Mesmo considerando tão singular conhecimento para a formação humana e para a prática educacional, como posto pela própria BNCC, seu status e sua importância fazem-se totalmente incompatíveis com sua permanente situação de invisibilidade nas escolas públicas.

Paradoxalmente, o documento retrata que:

\footnotetext{
A arte contribui para o desenvolvimento da autonomia criativa e expressiva dos estudantes, por meio da conexão da racionalidade, sensibilidade, intuição e ludicidade. Ela é, também, propulsora da ampliação do conhecimento do sujeito relacionado a si, ao outro e ao mundo. É na aprendizagem, na pesquisa e no fazer artístico que as percepções e compreensões do mundo se ampliam no âmbito da sensibilidade e se interconectam, em uma perspectiva poética em relação à vida, que permite aos sujeitos estar abertos as percepções e experiências, mediante a capacidade de imaginar e ressignificar os cotidianos e rotinas. (BRASIL, 2017, p. 482).
}

Entre a legitimação desse valor atribuído à arte e sua efetivação concreta, no entanto, há um paradoxo, pois, quando na sua concretização, o que se revela é uma destituição de valor da arte e de suas linguagens, em particular da música e de sua prática nos currículos da nossa escola pública, fato este que nos causa indignação, mas também nos mobiliza a pesquisas em práticas que se apresentam como linhas de fuga dessa realidade a fim de promover novos contextos e realidades. 
Estudos de Fonterrada (2015, p. 16) confirmam que a presença da educação musical na educação básica brasileira é "quase inexistente", permanecendo na escola na forma de projetos circunstanciais e raras exceções, não exercendo um papel de destaque. Assim, consideramos imperativo dispor de tempos e espaços que ensejem a vivência de práticas criativas que promovam mudanças de atitudes indispensáveis para integrar a música ao currículo e promover, assim, uma cultura musical nas escolas - uma mudança de habitus que seja capaz de criar um enraizamento cultural que componha a formação dos estudantes e garanta sua estabilidade nas escolas públicas (KACZAN, 2017).

Por tal pretexto, apontamos argumentos contundentes em defesa da permanência da música e de seu ensino:

No obstante, en una lectura en profundidad se pueden entresacar algunos conceptos o ideas fundamentales para la defensa de la música en la Escuela como son: el carácter innato de la música en el ser humano; la música como experiencia global; el desarrollo parejo entre música y lenguaje (y cómo sin la música el lenguaje no podría desarrollarse); la contribución de la música al desarrollo personal, social y la calidad de vida; la música como generadora de identidad y la identidad como forma de conocimiento; el desarrollo creativo y por último, la capacidad emocional y de empatía desarrollada por la música. (PEÑALBA, 2017, p. 116).

Em uma perspectiva individual e coletiva, o ensino de música mostra-se como instrumento necessário ao desenvolvimento integral do estudante, sendo também relevante para a formação crítica e emancipatória dos sujeitos, para uma vida autônoma em sociedade e, principalmente, para a consolidação de uma cidadania planetária. Esta última, já assinalada por Morin (2011) como condição indispensável para a sobrevivência da humanidade, deve ultrapassar a dimensão cognitiva e contribuir para a redução do quadro de vulnerabilidade social, uma vez que a música é capaz de ampliar os sentidos e a cognição, promovendo a interação e o senso crítico, além de auxiliar no desenvolvimento socioafetivo.

Em busca da promoção do diálogo, tecemos aqui reflexões sobre o valor das práticas musicais criativas e as possibilidades de repercussões propositivas na formação de sujeitos mais críticos e emancipados socialmente, pois, em nosso entender, essa proposta se dá na contramão de um modelo de ensino proposto pelas atuais políticas educacionais brasileiras, que seguem a cartilha neoliberal de desmonte do sistema público de educação, excludente já em seu cerne, ou seja, que traz os sujeitos excluídos para dentro da escola e em seu interior reproduz a exclusão social (BOURDIEU; PASSERON, 1992), pois nem todos têm acesso à cultura e muito menos uma familiaridade com os elementos culturais. Para Bourdieu e Darbel (2003), são necessárias certas disposições adquiridas ao longo do tempo para que os indivíduos em sua totalidade vivam intensamente esse amor pela arte. A intenção de 
Pierre Bourdieu aqui é desvendar as condições sociais de acesso à cultura. Segundo ele, "[...] a cultura não é um privilégio natural, mas que seria necessário e bastaria que todos possuíssem os meios para dela tomarem posse para que pertencesse a todos." Afirma que a "necessidade cultural" (BOURDIEU; DARBEL, 2003, p. 9) é algo produzido na escola, fruto da educação, apontando o papel da escola na formação de uma cultura geral ampla. Uma das suas principais teses é afirmar que a escola auxilia na transmissão dos códigos da cultura erudita e vai transformar as desigualdades frente à cultura em desigualdades de sucesso dentro do ambiente escolar.

Baseamo-nos, portanto, na defesa e no compromisso da sociedade e da escola, ao propormos novos olhares para o ensino da música nas instituições públicas de ensino, uma vez que esse componente se configura em via e conteúdo pedagógico que potencializa o surgimento de subjetividades inquietas e engajadas socialmente, capazes de romper com o processo de alienação e/ou subordinação à lógica do mercado.

\section{PRÁTICAS CRIATIUAS DO ENSINO DA MÚSICA: CAMINHOS A CONSTITUIR}

0 motor central de nossas discussões é a necessidade de se reinventar o ensino de música, propondo práticas diversificadas que incentivem a criação e a fruição, que possam romper com o ensino tradicional de música e com a lógica do consumo mercadológico que o repertório comercial forma nos ouvintes. É necessário incentivar a criação de experiências diversas consideradas singulares diante do processo massivo que apenas reproduz modelos prontos e legitimados socialmente. Assim, é urgente investir em práticas criativas diversas, como as oficinas de músicas, os laboratórios de sons e a improvisação livre, distintas das atuais formas de ensinar música na escola.

Para explorar o vasto campo da educação musical e "afinar o mundo", como adverte Schafer (2011, p. 22), foi que enveredamos na experimentação da escuta dos sons como um novo caminho para se incorporarem mudanças essenciais nas práticas educativomusicais no atual cenário educacional. Segundo Schafer (2009, p. 17), "precisamos aprender a ouvir". Há uma urgente necessidade de se ouvirem os sons, para reencontrar caminhos, desvendar os segredos da "afinação do mundo". Essa proposta torna-se via de possibilidade para reafirmar a música como promotora de experiências "harmonizadoras dos sons do mundo sobre nós". Ainda de acordo com Schafer (2011), o ambiente acústico geral imprime significativas marcas, que moldam estilos de vida e comportamentos. É "um indicador das 
condições sociais" e pode "nos contar muita coisa a respeito das tendências e da evolução dessa sociedade." (SCHAFER, 2011, p. 23).

0 exemplo disso pode ser lido por meio da "paisagem sonora" no cenário musical da sociedade brasileira contemporânea, que exprime uma "miséria" cultural e impõe necessariamente a urgência de uma formação ampla capaz de promover uma mudança no status quo estabelecido nas atuais circunstâncias históricas.

"Só a arte pode fazer essas coisas. A arte pode elevar o homem de um estado de fragmentação a um estado de ser íntegro, total. A arte capacita o homem para compreender a realidade e o ajuda não só a suportá-la como a transformá-la." (FISCHER 1987, p. 57). Esse papel transformador da educação musical é reconhecido por notáveis estudos e foi identificado por Peñalba (2017), quando em suas pesquisas evidencia que por meio da música podemos colaborar para melhorar a

[...] atención, memoria, habilidades sociales, emocionales, fisicas y comunicativas de niños con necesidades educativas especiales. Los beneficios que la música puede aportar a nivel terapéutico son extrapolables al ámbito educativo, en el que nos deberíamos preocupar más por el bienestar físico, emocional y social de nuestros alumnos como prioridad con respecto al dominio de contenidos puramente académicos. El fin último de la educación es formar personas, ciudadanos que puedan vivir en sociedad, personas críticas y sensibles, creativas e imaginativas. (PEÑALBA, 2017, p. 122).

A partir dessas análises, a implementação de práticas educativo-musicais criativas se configura como a alternativa mais adequada ao ensino de música nas escolas, capaz tanto de fortalecer o campo da educação musical quanto de promover maior interação da música com outras linguagens da arte. Dessa maneira, consideramos que as possibilidades trazidas por experimentações, vivências e envolvimento em práticas musicais diferenciadas no ensino de música são essenciais à promoção de conhecimentos, possibilitando aos educandos um despertar crítico da realidade na qual estão hodiernamente inseridos.

De acordo com Penna (2014), a defesa do ensino criativo de música no Brasil se materializou por volta da década de 1960 com um grupo de educadores musicais e compositores - teóricos da corrente de renovação da música erudita. Eles procuraram aproximar crianças e jovens de novas sonoridades, ampliando o universo musical desses alunos e dando-lhes acesso a maior variedade de ritmos e amostras musicais por meio de um fazer criativo que atribuiu uma nova feição para o ensino de música, o que se refere às “Novas poéticas e novas formalidades que subvertem completamente a lógica de uma escrita tradicional agora insuficiente e estreita para as necessidades criadas por obras que jogam com materialidades e modelos conceptuais que não têm precedentes." (LOPES, 1990, p. 1). 
Por ora, essa discussão inaugura um momento no campo musical e traz possibilidades diversas para seu ensino. Assim, foram sugeridas por professores renomeados, como Schafer, (2009), Fonterrada, (2019) e Penna (2014), formas diversas de se organizarem os sons, como "em série, blocos, massas, texturas etc." (PENNA 2014, p. 26), com extrema relevância da participação criativa do executor e/ou intérprete musical. Essas propostas foram implantadas por esses professores em projetos, estudos acadêmicos e salas de aulas, visando a afastar-se dos procedimentos tradicionais para, desse modo, incentivar a espontaneidade e a criatividade. Trata-se de maneira diversa de executar novas sonoridades musicais que se distanciam do padrão de música tonal, ecoando, para alguns, no entanto, de modo estranho, por não estarmos familiarizados com seus princípios organizativos, mas sonoridades que cumprem a função de abrir campos de possibilidades nessa área.

Essa vertente teórica de vanguarda da música erudita contemporânea foi significativa para ampliar o material sonoro e apontar novos caminhos e recursos que foram sendo incorporados ao cotidiano da prática de ensino musical, reconfigurando o espaço do fazer docente. Assim, podemos citar expressões desse novo fazer docente alicerçado na exploração inventiva de materiais sonoros diversos propostos em "oficina de música", igualmente reconhecida por "laboratório de som" ou "experimentação sonora" (PENNA, 2014, p. 27).

Essas práticas denominadas práticas criativas foram significativas para ampliar 0 material sonoro e apontar novos caminhos e recursos que foram sendo incorporados ao cotidiano da prática de ensino musical, reconfigurando o espaço do fazer docente (PENNA, 2014).

Segundo Fonterrada (2015, p. 17), as ideias desses autores foram importantes para que o aluno aprendesse "[...] a escutar, a vivenciar a música e a experimentar ideias próprias em suas propostas musicais" e, dessa forma, "[...] desenvolver a capacidade de utilizar a linguagem musical de maneira autônoma, aperfeiçoar a escuta, a autoconsciência e o espírito crítico."

No entender de Fonterrada (2015, p. 19),

Os procedimentos em geral utilizados nas práticas criativas e na Improvisação Livre incentivam a escuta, a tomada de decisões, o desenvolvimento da autonomia, o reconhecimento de si e do outro, por meio de propostas que priorizam a invenção musical e o improviso; além disso, seu caráter prático e musical atrai os participantes que, em geral, se atemorizam quando se defrontam com o caráter tecnicista encontrado em muitas aulas de música.

Schafer (2009) considera a criação musical (improvisação livre) fundamental para o ensino de música, por isso tece uma crítica ao ensino tradicional que, em seu entender, enfatiza a repetição e não estimula o pensamento criativo, fazendo com que as propostas 
de ensino na escola se transformem em instrumento reprodutor de práticas rotineiras e repetitivas.

"As práticas criativas parecem mais adequadas para uma introdução do ensino de música nas escolas como também para o fortalecimento de sua prática. Além de promover uma interação entre a música e as outras linguagens da Arte." (FONTERRADA, 2015, p. 17). Nesse sentido, apresentamos a relevância dessa proposta de educação centrada na possibilidade de uma formação da sensibilidade e da ascese cultural dos educandos, a priori. Quando garantimos a presença do ensino de música nos espaços escolares, podemos pensar e produzir algo ainda maior, como, por exemplo, a promoção de uma cultura musical e seus benefícios para os estudantes.

Diante de tal constatação e de sua complexidade, reconhecemos ser importante afirmar nosso posicionamento, que defende a presença de práticas educativo-musicais criativas que promovam o desenvolvimento de um habitus musical como elemento que contribui efetivamente para a inserção e participação social ativa dos sujeitos, bem como para possibilidades de elevação de crítica social, cidadania, emancipação e inclusão. Temos na música possibilidades de constituição de um habitus musical na formação humana de sujeitos-devir.

\subsection{O ENSINO DE MÚSICA E A FORMAÇÃO DE UM HABITUS MUSICAL}

As discussões sobre o ensino de música e sua possibilidade de favorecer a formação de um habitus musical nos remetem inevitavelmente ao papel que a escola assume no atual contexto político, econômico e social. A escola, instituição criada na e para a sociedade, enquanto bem de consumo, tem a função primordial de socialização da cultura letrada e difusão do legado cultural socialmente estabelecido no decorrer do processo histórico.

As análises de Bourdieu (2001) que tratam da produção, da distribuição e do acesso aos bens culturais e simbólicos, entre eles os que se desenvolvem no universo escolar, área privilegiada na análise desse autor, consideram a cultura como uma dimensão fundamental na compreensão da lógica que estabelece o domínio cultural em uma hierarquia social. A escola se constitui como principal reprodutora dessa relação de domínio que não é explícita, pois nas atuais circunstâncias históricas o sistema escolar que a priori deveria incluir é o mesmo que reproduz as condições de subordinação e exclusão. Muitos dos mecanismos que atuam no cerne do sistema de ensino em geral concorrem para reforçar o quadro de exclusão e seletividade social a que educandos, em sua maioria, já estão sujeitos hodiernamente. 
A escola, ao operar com suporte no sistema de apropriação de símbolos culturais originários do cotidiano familiar do educando, como matriz formadora de um habitus desenvolvido a partir das circunstâncias históricas - história de vida concreta dos estudantes, de grupos ou instituições sociais - poderá cumprir sua função envolvendo somente aqueles que possuírem uma competência social prévia, entendida como pressuposto para o aprendizado e para a formação de um habitus cultural.

É condição sine qua non conhecer os mecanismos de reprodução e exclusão social (BOURDIEU, 1992) e, assim, por meio do desenvolvimento de uma cultura musical diversa do socialmente posto como padrão, propor o estabelecimento da competência musical como um processo pedagógico orientado que busque romper com as estruturas sociais instituídas.

Desse modo, a escola precisa atuar no sentido de operar para formar essa competência prévia no estudante, ressignificando aprendizagens e favorecendo um desempenho global, cumprindo sua função essencial: formar sujeitos ativos e engajados socialmente - constituir sujeitos autônomos com uma consciência crítica que perceba a lógica estrutural do sistema, formados num processo cultural amplo.

Em seu aspecto formal, o habitus é definido como uma "propriedade" dos diversos atores ou grupos sociais. Ou seja, "[...] uma estrutura estruturante [...] estruturada que organiza as práticas e a percepção das práticas." (BOURDIEU, 2007, p. 57). Tal definição nos conduz a um campo teórico no qual Bourdieu define as bases desse conceito. Assim, o habitus é uma propriedade que

\footnotetext{
[...] é "estruturada" pelo nosso passado e circunstâncias atuais, como a criação na familia e as experiências educacionais. Ela é "estruturante" no sentido de que nosso habitus ajuda a moldar nossas práticas atuais e futuras. Ela é uma "estrutura" por ser ordenada sistematicamente, e não aleatória ou sem nenhum padrão. Essa "estrutura" é composta de um sistema de disposições que geram percepções, apreciações e práticas. (MATON, 2018, p. 75).
}

Por seu turno, o habitus é conformado pelas condições reais de existência que produzem necessariamente o conjunto de valores e crenças pactuado em seu próprio arcabouço. Conforma um "capital cultural" em um "estado incorporado" (BOURDIEU, 1998, p. 71, 79).

A formação social desse habitus cultural no universo da escola promove uma cultura capaz de transcender uma série de "[...] dicotomias profundamente enraizadas que moldam os modos de pensar o mundo social." (MATON, 2018, p. 73). Nesse sentido, a aquisição da cultura torna-se imprescindível para o desenvolvimento integral dos sujeitos e da formação humana. Nesse horizonte, temos como paradigma a defesa de que o acesso e as vivências de práticas musicais concorrem para a constituição de um habitus musical - 
basilar no estabelecimento de um "capital cultural incorporado" (BOURDIEU, 1998, p. 72) - capaz de promover maior autonomia aos sujeitos cognoscentes.

A educação musical no ambiente escolar se configura como via de possibilidade do desenvolvimento de uma "competência social", que traz consigo uma riqueza de significados, promotora do desenvolvimento integral dos sujeitos. Ao ser introduzida uma educação musical no cotidiano escolar, desenvolve-se nos jovens uma cultura na qual estes se tornam "criadores de cultura" (BASTIAN, 2009, p. 35).

No campo específico do ensino de música, esse mecanismo opera na contramão do que é proposto hoje na sociedade neoliberal, uma vez que nesse modelo de sociedade os acessos aos bens culturais não são igualmente difundidos e socializados a todos indistintamente. A possibilidade de experiências musicais propositivas vivenciadas em contextos escolares torna-se significativa para o "refinamento de esquemas de interpretação" (BOURDIEU; DARBEL, 2003, p. 71-74) que colaboram para o recrudescimento da formação de um habitus cultural, diverso do proposto pela sociedade em geral.

Desse modo, Penna (2014, p. 31) afirma que

[...] a compreensão da música, ou mesmo a sensibilidade a ela, tem por base um padrão culturalmente compartilhado para a organização dos sons numa linguagem artística, padrão este que, socialmente construído, é socialmente apreendido - pela vivência, pelo contato cotidiano, pela familiarização, embora também possa ser apreendido na escola.

Corroboramos a compreensão de Penna (2014), quando esta defende o argumento de que, ao promovermos a educação musical no universo escolar, estabelecemos meios que permitem aos alunos se apropriarem de conceitos, desenvolvendo e ampliando

\footnotetext{
[...] os instrumentos de percepção necessários para que o individuo possa ser sensivel à música, apreendê-la, recebendo o material sonoro/musical como significativo. Pois nada é significativo no vazio, mas apenas quando relacionado e articulado ao quadro das experiências acumuladas, quando compatível com os esquemas de percepção desenvolvidos. (PENNA, 2014, p. 33).
}

Nosso entendimento é o de que a prática da educação musical promove habilidades e potencialidades específicas do ser humano, fundamentais para a sua vida em sociedade, como também propicia o desenvolvimento cognitivo, alarga o raciocínio lógicomatemático, aumenta o poder de concentração e modifica sua forma de agir e interagir no mundo multicultural de hoje. 
À música é atribuída a possibilidade de ampliação das capacidades cognitiva, relacional, motora, social e afetiva. Além disso, promove o desenvolvimento e a aprendizagem dos sujeitos e pode, em uma instância mais direta, contribuir para a superação dos muitos desafios educacionais contemporâneos: dificuldades de concentração e de aprendizagem, desinteresse pelas atividades escolares, evasão, indisciplina, entre outros obstáculos evidenciados no ambiente escolar.

Tal reflexão nos conduz à compreensão de que mudanças de atitudes e práticas escolares são indispensáveis para garantir o ensino de música no currículo e a possibilidade de instauração de uma cultura musical que implique uma educação promotora da formação de sujeitos omnilaterais. ${ }^{5}$

\section{CONSIDERAÇÕES FINAIS}

Embora pareça lugar-comum reafirmar a importância da música e de todas as artes como promotoras do desenvolvimento individual que agem no coletivo, é necessário dar voz ao discurso que entoa a nota em defesa da inserção da música no currículo das escolas públicas e, com ela, a música, fazer soar novas possibilidades e reinventar a escola e, mais especificamente, o ensinar música.

Algumas colocações postas aqui necessitam ser destacadas como notas conclusivas: a inexorável urgência de estabelecer a música como disciplina obrigatória no currículo e assim dar-lhe o real valor que possui; a necessidade de se promoverem práticas criativas, no sentido de promover um habitus que possa favorecer uma cultura musical ampla, diversa da que é instituída pelas estruturas de dominação impostas pela sociedade que opera na lógica do mercado.

Destarte, trilhar novos caminhos e estabelecer um lugar específico para o ensino de música no currículo das escolas públicas brasileiras é tarefa que na hierarquia dos problemas ocupa lugar central, uma vez que, em nosso entender, a atual forma estabelecida deslegitima e secundariza o seu potencial inclusivo e socializador, reafirmando a presença de uma concepção neoliberal de educação fruto de um ideário político-econômico que se alinha aos interesses de organismos multilaterais e que visam, a todo custo, a mercantilizar processos educacionais. 
Nesse caso, uma reflexão crítica sobre tais estratégias se faz cada vez mais imperativa no tempo presente, pois sabemos que a ausência não só do ensino de música das escolas, mas de todas as linguagens - artes visuais, da dança e do teatro - é um prejuízo irreparável na formação humana e que, se houvesse um investimento maior e mais compromisso com o desenvolvimento do processo educacional, visando à promoção da cidadania, poderíamos minimizar o quadro social caótico e violento com o qual nos deparamos todos os dias. Indiscutivelmente, vemos a humanidade neste século distanciar-se ainda mais de um projeto de emancipação, que possa transformar, ou mesmo que seja capaz de compreender criticamente o sentido pleno da existência.

0 desenvolvimento social e econômico, bem como a complexificação das ciências e do conhecimento, que deveriam rimar com o desenvolvimento social e humano, distanciam ainda mais as pessoas de uma ética universal, ou seja, da possibilidade de estas exercerem uma ética universal em nossas relações, com maior respeito ao Planeta, à humanidade, ao diverso e ao plural.

A destituição de valor da arte e suas linguagens, em particular da música, e suas possibilidades de práticas nos currículos da escola pública, causa-nos indignação, mas também nos mobiliza a pesquisas e provoca práticas que sejam dissidentes, compreendidas como linhas de fugas promotoras de outros sujeitos. Até hoje, mesmo com tantas mudanças nas legislações educacionais, mantém-se uma importante lacuna para o ensino de música nos espaços de formação, o que se converte na necessidade de os agentes da área reafirmarem propostas que requisitem o devido espaço e tempo para a Educação Musical como área de conhecimento legitimada.

Portanto, inserir práticas educativo-musicais criativas no universo das escolas públicas é de sobeja relevância para formar subjetividades inquietas e engajadas no intento de promover uma efetiva transformação social. Com efeito, reafirma-se o valor das práticas criativas no ensino de música como possibilidade efetiva de uma transformação da realidade educacional e da reinvenção de uma cultura escolar.

\section{REFERÊNCIAS}

BRASIL. Ministério da Educação. Base Nacional Comum Curricular: Ensino Médio. Documento homologado pela Portaria n. 1.570, publicada no Diário Oficial da União: Seção 1, Brasília, DF, p. 146, 21 dez. 2017. Disponivel em: http://basenacionalcomum.mec.gov.br/wp-content/uploads/2018/04/BNCC_EnsinoMedio_embaixa_site.pdf. Acesso em: 4 abr. 2018.

BASTIAN, H. G. Música na escola: a contribuição do ensino da música no aprendizado e no convivio social da criança. Tradução: Paulo F. Valério. São Paulo: Paulinas, 2009. 
BOURDIEU, P. A distinção: crítica social do julgamento. São Paulo: Edusp, 2007.

BOURDIEU, P. A gênese dos conceitos de hábitos e de campo. In: BOURDIEU, P. 0 poder simbólico. Rio de Janeiro: Bertrand Brasil, 2001.

BOURDIEU, P.; DARBEL, A. 0 amor pela arte: os museus de arte na Europa e seu público. São Paulo: Edusp/Zouk, 2003.

BOURDIEU, P. Os três estados do capital cultural. In: NOGUEIRA, M. A.; CATANI, A. (org.). Pierre Bourdieu: escritos de educação. Petrópolis, RJ: Vozes, 1998. p. 71-79.

BOURDIEU, P.; PASSERON, J. C. A reprodução: elementos para uma teoria do sistema de ensino. Rio de Janeiro: Francisco Alves, 1992.

FISCHER, E. A necessidade da arte. Tradução: Leandro Konder. 9. ed. Rio de Janeiro: Guanabara, 1987.

FONTERRADA, M. T. de 0. Ciranda de sons: práticas criativas em educação musical. São Paulo: Unesp Digital, 2015.

FONTERRADA, M. T. de 0. Educação musical na educação básica - princípios e questões do ensino de música na contemporaneidade. In: JORNADA INTERNACIONAL DE ESTUDOS INTERDISCIPLINARES: MÚSICA, EDUCAÇÃO E SOCIEDADE, 2., 2019, Palência/Fortaleza. Anais [...] Fortaleza, 2019. Disponivel em: https:// photos.app.goo.gl/RtFt1LvvuNuiakkz6. Acesso em: 18 abr. 2019.

GRAMSCl, A. Os intelectuais e a organização da cultura. 4. ed. Rio de Janeiro: Civilização Brasileira, 1982.

KACZAN, M. Entrelaçando caminhos: histórias de vida dos professores de música em Fortaleza. 2017. 151 f. Dissertação (Mestrado em Educação) - Universidade Federal do Ceará, Fortaleza, 2017.

LOPES, J. J. As escritas da abertura na música contemporânea. [S. l.: s. n., 1990. Disponivel em: http:// www.bocc.ubi.pt/pag/lopes-jose-julio-escritas.pdf. Acesso em: 18 abr. 2019.

MATON, K. Habitus. In: GRENFEL, M. (ed.). Pierre Bourdieu: conceitos fundamentais. Tradução de Fábio Ribeiro. Petrópolis, RJ: Vozes, 2018. p. 73-94.

MORIN, E. Rumo ao abismo: ensaios sobre o destino da humanidade. Rio de Janeiro: Bertrand Brasil, 2011.

PEÑALBA, A. La defensa de la educación musical desde las neurociências. Revista Electrónica Complutense de Investigación en Educación Musical, v. 14, p. 109-127, 2017.

PENNA, M. Música(s) e seu ensino. 2. ed. rev. e ampl. Porto Alegre: Sulina, 2014. 
SCHAFER, R. M. A afinação do mundo: uma exploração pioneira pela história passada e pelo atual estado do mais negligenciado aspecto do nosso ambiente: a paisagem sonora. Tradução: Marisa Trench de Oliveira Fonterrada. 2. ed. São Paulo: Unesp, 2011.

SCHAFER, R. M. Educação sonora: 100 exercícios de escuta e criação de sons. Tradução: Marisa Trench de Oliveira Fonterrada. São Paulo: Melhoramentos, 2009.

Endereço para correspondência: Rua Professor Manoel Lourenço, 95, apto 303 B. Bairro Joquei Clube, Fortaleza, Ceará, Brasil; marcelokaczan@gmail.com

Roteiro, Joaçaba, u. 45, p. 1-16, jan./dez. 2020 | e23787 |E-ISSN 2177-6059 
